\title{
O Índice de Desenvolvimento da Educação do estado de São Paulo (Idesp): práticas escolares resultantes
}

The Development Index of São Paulo public Education (Idesp): school practices results

Luiz Carlos Gesqui*

Centro Universitário de Araraquara

Resumo Mensurado anualmente - com base apenas nas taxas de aprovação de todos os alunos e nos resultados de testes padronizados de uma parcela destes alunos - o Índice de Desenvolvimento da Educação no Estado de São Paulo (Idesp) indica, a partir de 2008, a qualidade da educação básica das mais de cinco mil escolas da rede pública paulista de ensino regular. O objetivo deste artigo é o de apresentar que as escolas, com base no Idesp, definem as práticas escolares a serem efetivadas das quais se destacam a excessiva aplicação de exames simulados e a promoção - pautada basicamente nos registros de frequência - dos alunos para a série seguinte. Tal afirmação é possível a partir de participações em reuniões pedagógicas em quatro destas escolas, no período de 2008 a 2011.

PALAVRAS-CHAVE: Qualidade educacional; Escola pública; Idesp.

Abstract Annually measured - based only on all students approved rates and the results of standardized tests of part of these students - the Education Development, Index in São Paulo state (Idesp), indicates, from 2008, the quality of Basic education of more than five thousand of São Paulo public schools of regular teaching. The purpose of this article is to present that the schools, based on Idesp determinate the school practices to be made in which the excessive mock test are implicated promotion - guided primarily on attendance records - from the students to the following series. This statement is possible from our pedagogical meetings participation in four of these schools, from 2008 to 2011 .

KEYWORDS: Educational quality; Public school; Idesp. 


\section{Introdução}

Uma vez que todas as populações valem-se, direta ou indiretamente, de seus serviços, a escola pública ainda hoje ocupa destacada importância na sociedade contemporânea, o que se revela por diversos indicadores. Note-se, de antemão, a função social primordial da escola: como preparo das gerações sempre renovadas para acesso ao saber sistematizado acumulado pela humanidade, com as crianças e adolescentes frequentando-a obrigatoriamente por um longo período de suas vidas, conforme aponta Jackson (1996). Sim, pois é na escola que as crianças mais ocupam o seu tempo, afora a família. Essa instituição, supõe-se então, possibilita seu ingresso no mundo da escrita e do conhecimento sistematizado. Isso não impede que as escolas venham, também, principalmente nas últimas décadas, sendo fonte de inúmeros questionamentos por parte de pais, alunos, sociedade e imprensa em geral quanto ao cumprimento desses serviços prestados por elas. Merece destaque, dentre os mais variados questionamentos, o que se expressa nos indicadores oficiais das avaliações educacionais externas, isto é: o que de fato revelam estes indicadores?

Esses números apresentados revelam efetiva aprendizagem dos alunos? Essa é uma das complexas e recorrentes questões que percorrem os ambientes escolares e imprensa de modo geral, porém, o objetivo do presente artigo é o de destacar outra questão, igualmente importante, só que pouco discutida. Trata-se de toda a atenção dispensada às avaliações externas (debates, aplicação e divulgação dos resultados) em prol de uma possível melhora nos indicadores destas avaliações. Segundo seus propositores, resultaria numa educação de qualidade, no entanto, priorizam resultados estatísticos ocultando, inclusive, alterações significativas nas práticas escolares em vista disso.

As informações utilizadas na elaboração deste artigo foram obtidas com a participação em diversas reuniões pedagógicas realizadas em várias escolas da rede pública paulista de ensino regular, no período de 2008 a 2011, reuniões estas cujo tema central era a análise, por parte de cada escola, dos indicadores do Índice de Desenvolvimento da Educação do Estado de São Paulo (Idesp). Busco com essas informações uma possível relação entre os resultados das avaliações externas e as mudanças significativas na definição e condução de práticas escolares observadas nessas escolas.

Num primeiro procedimento, foram organizadas e ordenadas, em função de seu Idesp 2008, vinte e nove (29) escolas da rede pública paulista de ensino regular. Isto com o objetivo de selecionar para o segundo procedimento duas escolas com Idesp expressivos e duas escolas com Idesp inexpressivos. No segundo procedimento, as práticas escolares recorrentes - identificadas por meio do relato dos participantes e dos registros nas pautas das reuniões de 2008 - são analisadas. O acompanhamento da efetivação e desdobramentos destas práticas foi realizado a partir das informações obtidas com a participação em reuniões pedagógicas nas escolas selecionadas ao longo dos quatro (4) anos. De modo geral, o Idesp das escolas - expressivo ou não - determina as práticas escolares desde que apontem para a melhora no Idesp. 


\section{Situando o problema}

As últimas décadas do século XVIII, marcadas principalmente pela revolução industrial, na esfera econômica, e pela revolução francesa, na esfera política, foram decisivas para transformações significativas no modo de vida do mundo ocidental, de imediato, e de praticamente toda a humanidade de lá para cá. Tais transformações significativas resultaram em transformações nas relações sociais, entre as quais a separação e os conflitos entre as classes sociais e o surgimento do trabalho livre em contraste com o trabalho escravo. São destacáveis: o êxodo humano do campo para os centros urbanos; da manufatura artesanal para a produção industrial; da troca de mercadorias para a compra e venda de produtos e a transferência do poder absoluto dos monarcas e da Igreja para o povo, ao menos formalmente.

A julgar, por exemplo, pela monarquia e pela Igreja, a consolidação dessas transformações certamente não ocorreu sem resistências por parte de instituições consideradas fortes até então. Contudo, para o fortalecimento da nova ordem social, pautada não apenas nas premissas da liberdade, igualdade e fraternidade, mas, principalmente na ideologia capitalista imanente à sociedade industrial, alguns segmentos inexistentes ou inexpressivos, como a fábrica e a escola, foram elevados, por diferentes motivos, ao status de instituições importantíssimas.

A possibilidade de transferir para a fábrica (que passa a ser o local onde os indivíduos podem facilmente visualizar algumas mudanças comportamentais, como o emprego assalariado ou o desemprego, que contribuem para as citadas transformações significativas) a suposta causa principal dessas mudanças comportamentais, ocasionou alguns enfrentamentos ou manifestações contrárias de alguns grupos. Isso se resolveu por meio de negociação ou uso da força. Entretanto, já ocorriam (e talvez ocorram até hoje de modo intenso dentro das escolas) mudanças comportamentais de maior significado e consequências, como a instalação da ideologia da sociedade industrial não só por meio da fábrica, que não foram facilmente visualizadas por esses mesmos indivíduos nem tão pouco se tornaram motivos de enfrentamentos significativos.

Mas, a obrigatoriedade à instrução primária não conferiu nenhum avanço intelectual, melhores perspectivas no trabalho ou melhoria nas condições de trabalho às crianças, mesmo com a instituição escolar, ou a escola como sua expressão objetiva das necessidades da sociedade capitalista e da indústria, tendo se tornado, por diversas razões, local de passagem obrigatória para crianças de todo o mundo.

Aos poucos, a emergente sociedade industrial vai definindo as características da escola. E, assim, não só atendendo a necessidade de inculcar nos mais jovens o comportamento esperado para as fábricas, como também servindo para cristalizar junto à sociedade, pressupostos de uma racionalidade tecnológica indispensável para eficiência e controle do sistema produtivo. Nesse caso, a escola tem papel decisivo. Marcuse (1979) afirma que as respostas que o indivíduo oferece a essas situações não podem ser consideradas próprias, e sim resultantes de um contínuo processo de doutrinação e manipulação presentes na civilização industrial desenvolvida. 
Há um crescimento exponencial da oferta educativa escolar, o aumento da procura pela escola e a ampliação das políticas educativas globais, após a Segunda Guerra Mundial. Segundo indicadores nacionais, o Brasil também segue essa tendência, pois os dados do Instituto Brasileiro de Geografia e Estatística de 1970, por exemplo, apontam que, no período de 1950 a 1970, a população brasileira passa de 51.944.937 para 94.501.554 habitantes (aumento de 82\%), a população com idade entre 5 e 19 anos vai de 18.826 .409 para 35.170 .643 habitantes (aumento de 87\%) e o número de matrículas para essa faixa etária salta de 4.924 .226 para 18.896.260 (aumento de 383\%). Como financiar, administrar, "democratizar" e, principalmente, assegurar que a escola não perca características até então importantes para a ideologia da sociedade industrial vigente?

A essa altura, visto ter assumido proporções, valores e custos financeiros impensáveis há cem anos, o tema educação é entregue à competência de organizações mundiais. Encerrada a Segunda Guerra Mundial, países que se firmaram, econômica e politicamente, criaram instituições a exemplo do Banco Mundial, que tem como objetivo declarado reduzir a pobreza e cujas funções, entre outras, são determinar o que e como ensinar, a quem e por quanto tempo ensinar, quem e com qual formação ensinar e, o principal, com que custo financeiro. A preocupação pedagógica, social e cultural da educação sucumbiu frente ao valor econômico que esta alcançou, é o que afirma Tommasi (1996).

Tal afirmação justifica-se ao observarmos que a escola pública de diversos países foi pouco a pouco organizada em decorrência de orientações feitas por essas instituições internacionais. No caso brasileiro, é uma escola que integra uma rede numerosa, amparada por uma legislação federal que segue um conjunto de orientações (principalmente do Banco Mundial), o que resulta em uma série de consequências, observadas nas escolas. Eis algumas: aumento do número de alunos por sala de aula, os baixos investimentos em salários de professores, a utilização desenfreada do livro didático como principal recurso em sala de aula, a redução ou terceirização do quadro de funcionários e as práticas de validação da metodologia utilizada.

A partir da década de 1990, entre as referidas práticas de validação da metodologia utilizada, destaca-se a grande ênfase dada às avaliações em larga escala, especialmente as avaliações externas, e observadas, por exemplo, no exame do Programa Internacional de Avaliação de Alunos (Pisa), ou nas avaliações em larga escala internas, no caso brasileiro expressas no Exame Nacional do Ensino Médio (Enem), ou nos indicadores do Índice de Desenvolvimento da Educação Básica (Ideb), por exemplo. No caso do Estado de São Paulo, o indicador Idesp cumpre este papel. Que essas práticas, ou essa cultura de avaliação, possam ser entendidas como uma expressão da racionalidade tecnológica da sociedade industrial aplicada ao sistema escolar público, principalmente, é possível.

A implantação do Idesp, em 2008 pela Secretaria de Educação do Estado de São Paulo (SEE-SP), nas mais de 5.500 escolas de ensino regular e para um público aproximado de 5.000 .000 de alunos, ilustra algumas das considerações até aqui apresentadas, uma vez que propõe, ao menos oficial e publicamente, uma educação de qualidade a todos os alunos. 
O referido indicador faz parte do Programa de Qualidade nas Escolas (PQE) cuja principal finalidade, segundo a SEE-SP, é promover a melhoria da qualidade do ensino da rede estadual paulista e a equidade do sistema. Foi lançado pela Secretaria de Educação do Estado de São Paulo, em 2008 com "o objetivo de promover qualidade e equidade no sistema de ensino da rede estadual paulista" (SÃO PAULO, 2009 p. 1). Estabelece, basicamente, uma meta a ser alcançada anualmente, para cada escola pública de ensino regular, até o ano de 2030, data esta em que se espera que todas as escolas tenham atingido indicadores compatíveis com os encontrados atualmente em países da Organização para a Cooperação e Desenvolvimento Econômico (OCDE). O índice considera o fluxo escolar - coletado pelo Censo Escolar - e o desempenho dos alunos - medido pelos resultados dos exames de Língua Portuguesa e Matemática do Sistema de Avaliação de Rendimento Escolar do Estado de São Paulo (Saresp). O cumprimento das metas estabelecidas resulta na recompensa financeira para os profissionais da educação, por exemplo, o direito ao recebimento imediato do bônus merecimento. Contudo, o fato de uma escola cumprir a meta estabelecida, expressa pelos indicadores estatísticos, não permite a comprovação imediata de que agregou qualidade a seus serviços.

No que se refere à relação entre avaliação externa e conceito de qualidade educacional com indicadores estatísticos que expressem essa relação, Giovinazzo Jr. e Minhoto (2009) apresentam alterações observadas no conceito de qualidade no movimento histórico das políticas educacionais, tendo por base o desenvolvimento das estatísticas educacionais até o início da década de 1970, que podem ser sintetizadas em três (3) momentos: universalização do acesso (o aluno para dentro da escola); diminuição da retenção e evasão (correção do fluxo e manter o aluno dentro da escola) e, finalmente, controlar o desempenho dos estudantes por meio de testes padrão. $\mathrm{O}$ trabalho de Dourado, Oliveira e Santos (2007), por sua vez, destaca a necessidade de que os indicadores estatísticos utilizados no campo educacional contemplem - e isso ainda não ocorre - fatores intra e extra escolares e, por fim, a investigação sobre a trajetória das avaliações externas no Brasil e seus indicadores, de Bonamino e Souza (2012), aponta para aperfeiçoamento dos procedimentos metodológicos do indicador em detrimento de uma possível aferição da qualidade educacional. A avaliação externa - que é baseada em testes padronizados - não capta todo o processo educacional, por conseguinte, não pode definir sozinha, o que é qualidade educacional. Deste modo, faz-se necessário uma definição clara do conceito de qualidade educacional para, posteriormente, aferi-la e aumentá-la.

\section{Questões metodológicas}

Verificar se o IDESP obtido pelas escolas da rede pública paulista de ensino regular, no ano anterior, ou a meta Idesp estabelecida pela SEE-SP, para o ano em curso, influenciam ou não na definição de práticas escolares - entendidas aqui como o conjunto de práticas administrativas e pedagógicas utilizadas pela escola em seu cotidiano - e identificar quais são estas práticas são as propostas deste artigo. Busco também possíveis relações entre o valor absoluto do Idesp em questão e sua influência na definição dessas práticas, ou dito de outro modo, difere a influência do Idesp para escolas com resultados considerados expressivos e escolas com resultados considerados inexpressivos? 
A expressão "escolas com resultados considerados expressivos", faz-se necessário destacar, é utilizada para caracterizar as escolas cujo Idesp 2008 foi classificado, em valores absolutos e de modo decrescente, entre a primeira e a décima quarta escola e que a utilização da expressão "escolas com resultados considerados inexpressivos" é utilizada para caracterizar as escolas cujo Idesp foi classificado entre a décima quinta e vigésima nona escola.

Em função desses questionamentos, foram analisados os indicadores Idesp do ensino médio, de todas as vinte e nove (29) escolas públicas da rede estadual de ensino regular, que atendem simultaneamente o ensino fundamental ciclo II e o ensino médio, de uma cidade do interior de São Paulo, referentes aos resultados dos anos letivos de 2008, 2009, 2010 e 2011 e informações obtidas com a participação em diversas reuniões pedagógicas realizadas em várias escolas.

No primeiro procedimento, após a classificação das escolas em escolas com o Idesp considerado expressivo e escolas com o Idesp considerado inexpressivo, foram realizados contatos com estas escolas e definidas as quatro (4) a serem utilizadas no segundo procedimento. No segundo procedimento, são apresentados alguns aspectos das condições em que as reuniões foram desenvolvidas, apresentam-se as duas práticas escolares - no caso a realização de elevado número de simulados e o aperfeiçoamento de mecanismos de controle de frequência de alunos - mais recorrentes e comuns as quatro (4) escolas pesquisadas e desdobramentos observados na efetivação das mesmas.

\section{Considerações referentes ao primeiro procedimento}

O primeiro destaque é observado quando da organização dos indicadores Idesp das vinte e nove (29) escolas para a seleção das escolas a serem pesquisadas, e verifica-se a grande diferença registrada entre a escola com o Idesp mais expressivo $(3,24)$ e a escola com o Idesp menos expressivo $(1,31)$. Outro destaque é o fato de a escola com o Idesp mais expressivo estar distante do valor ideal (5) proposto pela SEE-SP. A simples citação de escola com o Idesp mais expressivo poderia ser substituída, sem prejuízo algum, pela citação de escola com o Idesp menos inexpressivo.

Com o objetivo de oferecer uma visão do conjunto dos dados das escolas selecionadas, o quadro 1 apresenta informações de seis (6) escolas: a escola um (1), cujo Idesp 2008 é o mais expressivo dentre todas, a escola seis (6), cujo Idesp 2008 é o menos expressivo entre todas, e as escolas dois (2), três (3), quatro (4) e cinco (5), selecionadas para o segundo procedimento. No campo 1, a posição da escola em relação ao conjunto das demais; no campo 2, com o Idesp de 2008 e o campo 3 com a meta Idesp estabelecida pela SEE-SP para o ano de 2009. 


\begin{tabular}{|c|c|c|c|}
\hline Escola & Posição & IDESP 2008 & $\begin{array}{c}\text { Meta IDESP para } \\
\mathbf{2 0 0 9}\end{array}$ \\
\hline $\mathbf{1}$ & $\mathbf{1}$ & 3,24 & 3,32 \\
\hline $\mathbf{2}$ & $\mathbf{1}$ & 3,24 & 3,32 \\
\hline $\mathbf{3}$ & $\mathbf{6}$ & 2,83 & 2,91 \\
\hline $\mathbf{4}$ & $\mathbf{1 6}$ & 2,39 & 2,49 \\
\hline $\mathbf{5}$ & $\mathbf{2 3}$ & 1,94 & 2,04 \\
\hline $\mathbf{6}$ & $\mathbf{2 9}$ & 1,31 & 1,42 \\
\hline
\end{tabular}

Quadro 1: IDESP 2008 e metas IDESP para 2009 das escolas selecionadas.

Fonte: Elaborado a partir de Gesqui, 2012.

O Idesp observado das escolas selecionadas, por sua vez, na edição de 2008, era de 3,$24 ; 2,83 ; 2,39$ e 1,94, todavia, mesmo com valores tão diferentes, observou-se, durante as reuniões, que o cumprimento das metas, independente do valor observado, ganha destaque nestas reuniões, haja vista ser associado diretamente ao recebimento, ou não, para cada profissional da escola de um prêmio em dinheiro, denominado bônus merecimento, e à repercussão da divulgação pública destes indicadores junto aos profissionais da escola, aos alunos e à comunidade em que a escola está inserida. Em poucas oportunidades, e ainda assim em momentos isolados, o Idesp foi atrelado às questões de aprendizagem dos alunos, porém, em todas essas poucas oportunidades, a justificativa utilizada foi a de que as informações oferecidas pelo boletim do SARESP cumprem esta finalidade, pois contempla uma quantidade maior de séries, turmas e de componentes curriculares, todavia, não destacam que este boletim é disponibilizado meses após a divulgação do Idesp.

A análise do primeiro procedimento, de modo geral, aponta para o seguinte fato: independentemente de a escola apresentar um valor expressivo ou inexpressivo em seu Idesp, o cumprimento da meta, oficialmente proposta pela SEE-SP, tornou-se uma obsessão para estas escolas e seus profissionais, quer por motivos financeiros quer pela repercussão dos mesmos. Não se afirma aqui que os profissionais da educação são mercenários e que buscam apenas a recompensa financeira, todavia, dadas as condições objetivas de seus vencimentos, condições de trabalho e perspectivas de carreira, o prêmio financeiro torna-se inegavelmente um atrativo.

Não se afirma, outrossim, que estes profissionais definam seus procedimentos e atuação receosos quanto à opinião popular, mas o Idesp expressa publicamente um valor que, segundo a SEE-SP, mensura a qualidade da escola. Não divulga, porém, as condições objetivas da escola em questão. O que se entende aqui como indiscutível é que a escola, ao buscar o cumprimento da meta Idesp oficialmente proposta pela SEE-SP, torna secundária ou até elimina a discussão sobre o que, de fato, é uma educação ou um ensino de qualidade. 


\section{Considerações referentes ao segundo procedimento}

Ao longo do ano letivo ocorrem, semanalmente, em todas as escolas da rede pública paulista de ensino regular, o horário de trabalho pedagógico coletivo (HTPC) e foram nestas reuniões que ocorreu a maioria das participações do pesquisador. Cada escola foi visitada ao menos em três (3) oportunidades por ano, sendo a primeira após a divulgação anual do Idesp - o que ocorre geralmente no final do mês de março - e as outras duas no segundo semestre, principalmente em função da disponibilidade da escola. Em algumas oportunidades, as reuniões não ocorreram durante os HTPCs, resultando na dispensa de algumas, ou até todas, as turmas após as duas ou três primeiras aulas, para que toda a equipe escolar participasse das discussões.

Todas as reuniões ocorreram no período de 2008 a 2011, e, em algumas, o pesquisador participou como professor, noutras como gestor e noutras ainda como palestrante convidado. As reuniões, em sua maioria, resumiam-se a apresentação dos resultados da escola, comparação dos resultados da escola com os resultados da Diretoria de Ensino e da SEE-SP, levantamento dos possíveis fatores que contribuíram para a obtenção do índice e definição de práticas, preferencialmente imediatas, para melhorar o Idesp e, se possível, cumprir as metas oficialmente estabelecidas.

Em todas as reuniões, observou-se que as decisões mais citadas, e transformadas em práticas, escolares foram as de determinar, após a divulgação do boletim Idesp do ano anterior, a quantidade de alunos que pode ser retida no ano em curso, com o objetivo de assegurar um indicador de fluxo que não comprometa o indicador de desempenho dos alunos participantes e realizar diversos simulados de avaliações externas, como aposta para a melhora nos indicadores de desempenho dos alunos participantes.

Observou-se, no que se refere à definição da quantidade de alunos que pode ser retida no ano em curso, a construção e aperfeiçoamento dos instrumentos de controle diário da frequência do aluno. O Diário de Classe não é suficiente para o acompanhamento diário da frequência do aluno, considerando-se que suas informações, quanto à ausência dos alunos, será, na melhor das hipóteses, discutida depois de seguidas ausências do aluno. Observou-se, também, maior utilização do recurso de compensação de ausências, ou seja, uma prática raramente utilizada pelas escolas, ou utilizada apenas no último bimestre letivo, não aceita por parte dos professores, porém prevista legalmente, que é retomada praticamente sem resistências.

Observou-se, quanto à realização dos simulados, que todas as escolas incluem em seu planejamento uma série deles, com o intuito de preparar os alunos para as avaliações externas. Todavia, merece atenção a quantidade de simulados por escola, que em vários casos mantiveram, inclusive, os chamado provões. Ocorre, com regularidade, dada a complexidade para a elaboração dos simulados, a utilização de itens de edições anteriores do Saresp ou da Prova Brasil para elaboração desses simulados. Isso permite a hipótese de que, em alguns casos, os alunos podem ter participado no mesmo ano de simulados que utilizaram itens de simulados anteriores, porém, organizados de modo diferente. 
Ainda outra característica há que ser ressaltada. Refere-se ao fato de que para a elaboração dos instrumentos de controle de frequência ou dos simulados são utilizados, principalmente, os HTPCs, ou seja, o espaço destinado a discussões referentes ao processo de ensino e aprendizagem de todos os alunos da escola é utilizado somente para a organização e correção dessas atividades, que envolvem apenas parte dos alunos. Finalmente, observou-se que há turmas que não participarão dessas avaliações externas, turmas essas que, embora também tenham aulas ministradas pelos mesmos professores, que delas participarão como aplicadores, ficam relegadas a segundo plano em todos os aspectos, ou dito de outro modo, as turmas participantes das avaliações externas são prioridade na escola.

\section{Considerações finais}

Questões relacionadas à qualidade educacional aferida por avaliações externas e expressas por indicadores estatísticos, neste caso especificamente, por meio dos indicadores Idesp, tornaram-se motivos de inquietação socioeducacional nos últimos tempos por parte de educadores, o tema, porém, é frequentemente esquecido por parcela significativa dos profissionais da educação, que tendem, consciente ou inconscientemente, a afirmar que esses indicadores expressam qualidade educacional.

As informações aqui apresentadas, em especial as descritas nos procedimentos 1 e 2, apontam para uma relação direta entre os resultados das avaliações externas e as mudanças significativas na definição e condução de práticas escolares observadas nas escolas pesquisadas.

Os critérios utilizados na composição do indicador Idesp ocupam destaque no cotidiano escolar, porém, não é interessante para nenhum sistema educacional que, para o aluno aprender, seja necessário repetir uma ou várias vezes a mesma série, ou que o aluno seja promovido para a série seguinte com deficiências significativas de aprendizagem. Desta forma, ao utilizar um indicador de qualidade educacional, baseado apenas em dois critérios - fluxo escolar de todos os alunos e desempenho de parte de seus alunos em testes padronizados -, as escolas pesquisadas acabam por priorizar, em suas práticas escolares, apenas estes dois critérios como aposta para cumprir a meta Idesp oficialmente proposta pela SEE-SP.

A ampliação do número de variáveis na composição de um indicador educacional, no caso o Idesp, teoricamente possibilita um maior detalhamento da realidade da escola, o que não significa que quanto maior for o número de variáveis mais preciso será o indicador, todavia impossibilitaria situações como as expostas neste artigo. Somente pesquisas poderão definir quantas e quais variáveis serão necessárias para a construção de um indicador confiável de qualidade educacional, muito embora outras variáveis, como a localização geográfica da escola, o corpo docente, a equipe gestora ou a relação da escola com a comunidade, possam contribuir.

É possível que toda essa cultura de avaliação, expressa nos indicadores Idesp, represente apenas mais uma estratégia utilizada pela sociedade industrial e validada pela escola, para transformar em necessidade individual uma necessidade social, neste 
caso, o amplo controle do trabalho escolar. Marcuse (1979) afirma que as necessidades políticas de uma sociedade se transformaram em necessidades e aspirações individuais em função de um lento, gradativo e sutil processo de dominação do homem pelo homem, o que nos permite inferir que as práticas escolares resultantes nas escolas pesquisadas, em função do Idesp obtido e das metas estabelecidas, fazem parte deste processo.

Esses indicadores divulgados à comunidade escolar (alunos, pais, moradores da região, etc.) ficam sujeitos à sua interpretação, o que nos leva a outros questionamentos e novamente a outras hipóteses. Como isso se dá? Quais as consequências da forma como essa população interpreta esses indicadores? É possível que a apresentação dos indicadores e práticas observadas nas escolas, a partir dos resultados Idesp, possa contribuir para vislumbrar como a utilização de indicadores estatísticos, no campo educacional, pode ser direcionada a variados propósitos.

A comunidade escolar, ao interpretar como sendo positivos os resultados das práticas educacionais, neste caso expressos nos indicadores Idesp, na escola de seu filho ou de seu bairro, referenda, baseada em poucas e distorcidas informações, uma política educacional que talvez não tenha sido ainda suficientemente discutida pelos profissionais da educação, pelos diversos segmentos que a compõem ou simplesmente tal política não se aplique à sua realidade.

Nos mais variados meios de comunicação, a Secretaria de Educação do Estado de São Paulo divulga que aumenta, ano a ano, o número de escolas que alcançam as metas propostas para uma escola de qualidade em nosso Estado. Não divulga, entretanto, que esses indicadores, na maioria das escolas, estão muito aquém do ideal, mesmo quando em ascensão. Portanto, seja ela eficiente ou não, tal divulgação ampla, aliada a uma interpretação incorreta ou superficial de seus indicadores estatísticos, permite e respalda a manutenção da política educacional vigente.

Há muito tempo, indicadores educacionais nacionais, como o Ideb, e internacionais, como o Pisa, apontam para a real e urgente necessidade de uma política educacional que transforme, em curtíssimo prazo, a realidade educacional de nosso país. País este que mantém ainda grande parte da população com dificuldades para ler, escrever e contar com certa autonomia, todavia, ao observarmos as práticas escolares resultantes do esforço de um conjunto de profissionais da escola para a obtenção de indicadores estatísticos que, segundo seus propositores, definem se uma escola tem ou não qualidade, é muito difícil não questionar a validade destas práticas e, por conseguinte, destes indicadores.

Outros contextos - que vão além dos muros da escola - devem ser considerados, apesar de a busca pela qualidade na educação pública, no caso a paulista, certamente passar por ações e situações desenvolvidas dentro deles. Entre eles, a formação do indivíduo (HORKHEIMER, 2000), a constituição de uma massa de indivíduos (FREUD, 1972) e não de uma sociedade e, principalmente, pela efetivação de uma ideologia que não deixa o indivíduo contestar nenhuma das determinações da sociedade administrada, inclusive as referentes à escola. Uma escola de qualidade permite ao aluno, no mínimo, pensar e expressar opiniões. A cultura de avaliação e 
suas consequências não permitem isso ao aluno da escola pública. Oferecer uma escola pública de qualidade ultrapassa o treinamento de alunos para testes padronizados e garantia de uma trajetória escolar sem reprovação.

\section{Referências}

BONAMINO, A.; SOUZA, S. M. Z. Três gerações de avaliação da educação básica no Brasil: interfaces do currículo da-na escola. Educação e Pesquisa, São Paulo: v. 38, n. 2, 2012, p. 373388.

DOURADO, L. F.; OLIVEIRA, J. F.; SANTOS, C. A. Políticas e gestão da educação básica no Brasil: limites e perspectivas. Educação e Sociedade, Campinas: v. 28, n. 100, p. 921-946. 2007.

FREUD, S. Psicologia de las massas: más Allá del principio del placer. El porvenir de uma ilusión. 3. ed. Madrid: Alianza Editorial, 1972. 208p.

GESQUI, L. C. O índice de desenvolvimento da educação do Estado de São Paulo: a materialização da racionalidade tecnológica. Tese de Doutorado. São Paulo. PUC-SP, 2012.

GIOVINAZZO JÚNIOR, C. A.; MINHOTO, M. A. P. A qualidade do ensino na era dos indicadores: crítica da racionalidade tecnológica. In: XXV Simpósio Nacional de História, 2009, Fortaleza. Anais do XXV Simpósio Nacional de História - História e Ética. Fortaleza: ANPUH, 2009. CD-ROM.

HORKHEIMER, M. Eclipse da razão. São Paulo: Ática, 2000.187p.

JACKSON, P. La vida em lãs aulas. Madrid: Morata, 1996. 216p.

MARCUSE, H. A ideologia da sociedade industrial. O homem unidimensional. Tradução: Giasone Rebuá. Rio de Janeiro: Zahar, 1979.238p.

SÃO PAULO. Secretaria de Educação. Programa de qualidade na escola. São Paulo: 2009.08p.

TOMMASI, L. de; WARDE, M.; HADDAD, S. (Orgs.). O Banco Mundial e as políticas educacionais. São Paulo: Cortez/PUC-SP/Ação Educativa, 1996. 279p.

* Professor doutor do Centro Universitário de Araraquara, Araraquara, São Paulo, Brasil.

\section{Correspondência}

Luiz Carlos Gesqui - Centro Universitário de Araraquara. Rua Voluntários da Pátria - de 1045/1046 a 3165/3166. Centro, CEP: 14801-320 - Araraquara, São Paulo, Brasil.

E-mail: lgesqui@ig.com.br

Recebido em 10 de junho de 2014

Aprovado em 09 de março de 2015 